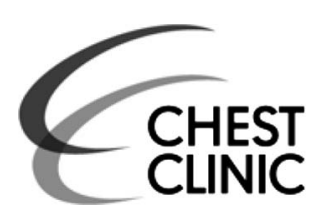

Department of General Thoracic Surgery, Catholic University, Rome, Italy

\section{Correspondence to}

Dr Dania Nachira, Department of General Thoracic Surgery, Catholic University, Rome 00168, Italy; danynac@libero.it

Received 19 October 2015 Accepted 16 December 2015 Published Online First 18 January 2016

\title{
Giant air-inflated hydatid cyst of the lung mimicking massive pneumothorax
}

\author{
Dania Nachira, Marco Chiappetta, Maria Teresa Congedo, Maria Letizia Vita, \\ Stefano Margaritora
}

A 68-year-old Caucasian man was admitted to our emergency department with a 6-month history of progressive dyspnoea, tachycardia, chronic cough and purulent sputum production. The patient's medical history was notable for hepatic echinococcosis diagnosed in 2002.

Physical examination revealed no chest wall movement, a hyper-resonant sound on percussion, absent tactile fremitus and no audible breath sound in the right hemithorax. A slight tracheal deviation towards the left could also be felt on palpation in the middle of the anterior neck behind the jugular notch of the manubrium.

The heart rate was $120 \mathrm{bpm}$, blood pressure $100 / 65 \mathrm{~mm} \mathrm{Hg}$ and $\mathrm{SpO}_{2} 92 \%$ on room air.

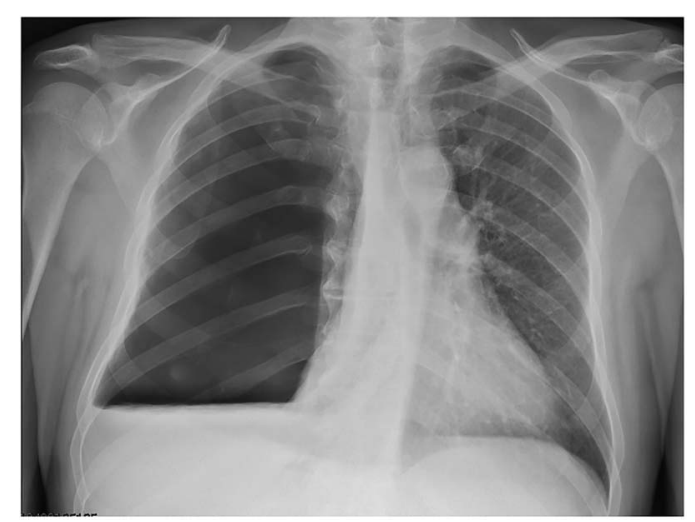

Figure 1 Chest radiograph showing a right massive hydropneumothorax.
A chest radiograph (figure 1) showed a massive right-sided hydropneumothorax that might have encouraged immediate chest drain insertion. However, there were no clinical features of tension pneumothorax, and the prolonged duration of the patient's symptoms and presentation alongside stable physiological observations suggested a chronic underlying cause.

The patient underwent a CT that revealed two hepatic localisations and a further giant air-filled hydatid cyst $^{1}$ of the right lower lobe (figure $2 \mathrm{~A}, \mathrm{~B}$ ) including a direct communication between the cyst and lateral basal subsegmental bronchi. The pulmonary cyst involved the complete right hemithorax, compressing the normal adjacent lung parenchyma.

The patient received albendazole therapy and subsequent surgical excision of the complete cyst ${ }^{2}$ via right thoracotomy, preserving the right lower lobe and packing the operative field with sponges soaked in scolicidal agents. The atelectatic right lung was completely reinflated although postoperative recovery was complicated by a prolonged air leak managed conservatively with a chest drain left in-situ for several days.

In conclusion, we report an unusual case of giant air-inflated hydatid cyst of the lung mimicking a massive pneumothorax. The case emphasises the importance of careful history-taking and clinical assessment, using second-line investigations such as CT in atypical presentations and potentially complex cases. This approach can help avoid
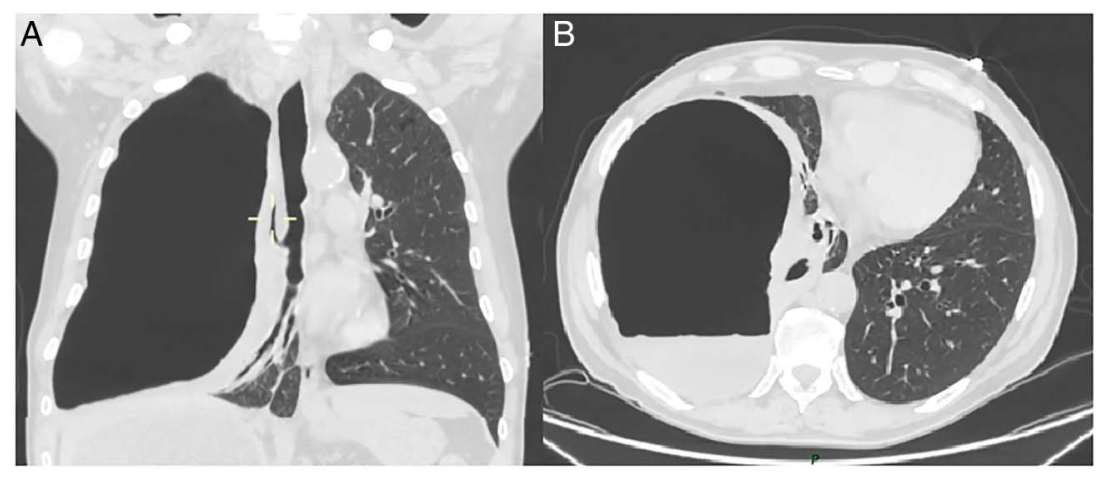

Figure 2 Coronal (A) and axial (B) CT scan of the chest showing a giant air-inflated hydatid cyst of the right lower lobe. 
inappropriate intervention that might otherwise complicate further treatment and recovery.

Competing interests None declared.

Patient consent Obtained.

Provenance and peer review Not commissioned; externally peer reviewed.

\section{REFERENCES}

1 Aletras H, Symbas PN. Hydatid disease of the lung. In: Shields TW, LoCicero J, Ponn RB, eds. General thoracic surgery. 5th edn. Philadelphia: Lippincott Williams \& Wilkins, 2000:1113-22.

2 Dogan $R$, Yüksel $M$, Cetin $G$, et al. Surgical treatment of hydatid cysts of the lung: report on 1055 patients. Thorax 1989;44:192-9. 